International Journal of Engineering \& Technology, $7(2.14)(2018) 70-73$
International Journal of Engineering \& Technology
SPC
Website: www.sciencepubco.com/index.php/IJET
Research Paper

\title{
Improving Information management in resource as a service framework using gamification technique: a case study in Institut Pendidikan Guru Malaysia
}

\author{
M Nordin A Rahman* and WM Khairi W Awang \\ Faculy of Informatics \& Computing, Universiti Sultan Zainal Abidin, Besut Campus, 22000 Besut, Terengganu \\ *Email: mohdnabd@unisza.edu.my
}

\begin{abstract}
The issue of information management is crucial for any academic institution. Convenient access to requested content is creating a competitive advantage for different types of decisions. Information management process in Institut Pendidikan Guru (IPG) often create problems because there is no systematic way of storage management. IPG lecturers stored their teaching materials in different kind of methods. This situation cause in a loss of resources, difficult to retrieve and also cannot be identified when it's needed. Dealing with large volumes of resources it is essential to use technological solutions that enable flexible storage, retrieval, processing and interpreting information. To solve the problems, this article introduced a framework that use single platform and named as Information Sharing for Learning (IS4L) for managing teaching and learning resources in IPG. The resources will be stored and can be accessed at any time. The framework also applied the technique of gamification to motivate and encourage users to use the application and consequently will increase the volume of resources stored. The developed application based on the proposed framework could help to motivate and engage peoples to share their resources and enhance quality of services in IPG. Finally it could assist to improve the performance and effectiveness of services to achieve users' satisfaction.
\end{abstract}

Keywords: Gamification; Information Management; Information Sharing; Resource as A Service.

\section{Introduction}

The use of technology is gradually increasing in education especially with the use of Information and Communication Technology (ICT). The printed materials such as books are replaced with digitized books, animations, video lectures which gives a better engagement to the users. ICT leads to greater benefits as in cost reduction, enhanced learning outcome and also in environment protection by reducing the use of papers. The emerging of ICT also triggered Institut Pendidikan Guru (IPG) to make changes in administration and provide services with computing-oriented platforms with greater flexibility in accessing and delivering resources over the Internet. This platform is expected to provide the way to access the content and deliver the content across the world, so it can be used in institutions for delivering the e-contents and sharing the resources such as digital libraries.

This approach can be defined as a Resource as a Service (RaaS) so that all users especially students can easily access the contents, learning materials and share the resources over Internet facilities. The efficiency and performance of IT-based product design applications are improved from time to time. There are several features that can be recognized in computing transactions as in storage management and sharing services. A big challenge faced in IPG is to convince lecturers to share or collaborate their teaching resources and materials. This behavioral problem is often too much to overcome regardless how powerful the information management solution in the organization sought to deploy.

Sharing resources activities are becoming a trend because the availability of effective platforms such as social networks and standard educational application management etc. Information sharing has become second-nature in our personal and professional lives via Facebook, Twitter and Linked [1]. However, the greatest challenge in information sharing is to encourage people to share their information consistently. It need a specific method or technique to attract them to participate in the process of information sharing.

This article is organized as follows: section 2 describes related work on resource as a service. Section 3 explains the concept of gamification technique, Section 4 illustrates the proposed framework in detail. Finally, conclusion is placed in Section 5.

\section{Resource as a Service}

The Resource as a Service (RaaS) is a model of cloud computing that allows providers to trade individual resources for a group of potential consumers. In the RaaS, users are able to purchase exactly the resources that needed [2]. The concept of RaaS has become an important area in organizations today especially in academic institutions like IPG. RaaS has eventually become a type of innovation that is adopted in the operation of the organization. IPG, as an institution which deals with academic knowledge must also 
adapt to this innovation not only to accommodate their academic purposes, but also for administration purposes of the institution.

It is important to note that the use of RaaS does not automatically translate to development of a conducive academic environment but the activities performed within RaaS such as collaboration, interaction, monitoring the progress of students, downloading as well as uploading of academic materials. It also will lead to an improved academic environment and consequently improve the performance of students [3].

For students to do well in their academic activities, effective learning is very important. Recently, ICTs are becoming important tools that aid student's effective learning. Effective learning encourages reflection, allows dialogue, promotes collaboration, applies theories learned into practice, creates a community of peers, allows creativity, as well as motivating students [4]. Designing a RaaS begins with defining the essential services for RaaS in the digital platform.

In the proposed framework of RaaS cover a digital platform which consists of six components explained in the following section. As shown in Figure 1, users are connected to the platform through Internet. They can access the resource service directory that contain different resource services such as information pre-processing and storage, analysis and sharing. Based on user's service choice and registration, resource service requirements are then sent to the platform manager, which finds out the suitable configuration of resources that are based on service-level-agreement (SLA). The resource allocation manager then allocates the resources to a set of physical machines to run the resource web service tasks.

The resource service tasks outputs in searching results, upload, download etc. are finally transmitted to the user through the web browser. After the resource applications or services are started, the system monitoring function tracks the resource usage that are attributed to users. It can also notify the resource and system managers for a quick response, and the resource configuration to assure that the correct resources are distributed to suitable users.

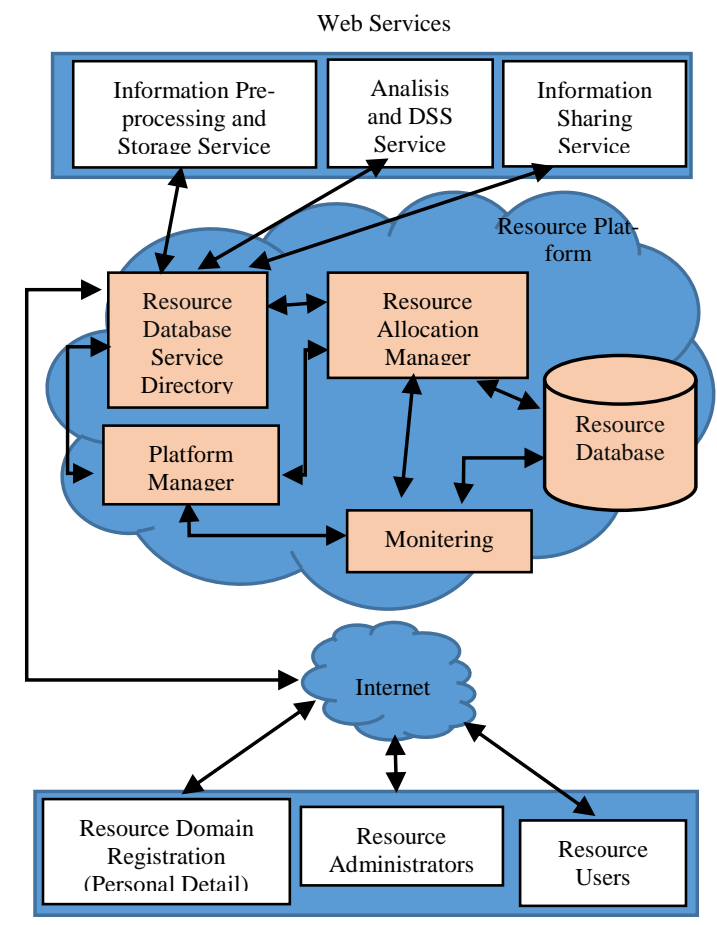

Fig. 1: System architecture of the proposed RaaS

\section{Gamification Technique}

Gamification is the application of game principles and mechanics in design fields in order to improve users' motivation and engagement [5]. Gamification is a very popular in modern design technique and has also been applied as a method for data collection and for tasks that require human intelligence [6][7].

In order to implement and examine the strategy to improve gamification practices, a multi-purpose platform called "Information Sharing for Learning" (IS4L) will be developed. The goal of the platform is to support the gamification process for academic activities in IPG. Four categories of participants are considered:

- Lecturers can use the platform to introduce or promote their teaching aids or notes;

- Students can use it to discuss, download any information and upload their projects and ask for feedback;

- Public users, can interact with the educational content and context, finally,

- Top management can manage the lecturers and students for cooperation opportunities or download any material.

IS4L is designed with the purpose to encourage the participation of lecturers and students, in an information building process such as searching for results, uploading, and downloading information. The concept of platform structure of IS4L is depicted in Figure 2. The participation of each activity is rewarded with points. From accumulated points, user can convert to bonus which are medals (gold, silver and bronze), depending on the activity. As the user accumulates medal, this allow users to represent the achievements of participation in the process of information construction. The medals are categorized according to the target of the game mechanics. Based on the total medal collected, the user will be ranked into the top 10 list. The activities of building information are as follows:

- Submit: Register a new practice, which can result from an individual effort.

- Socialized: Register a comment or suggestion for a new practice "submit".

- Re-Submit: Register an updated practice, after from the contributions of other users.

- Downloading: Register downloading any materials

- Uploading: Register an upload of any materials based on user's need.

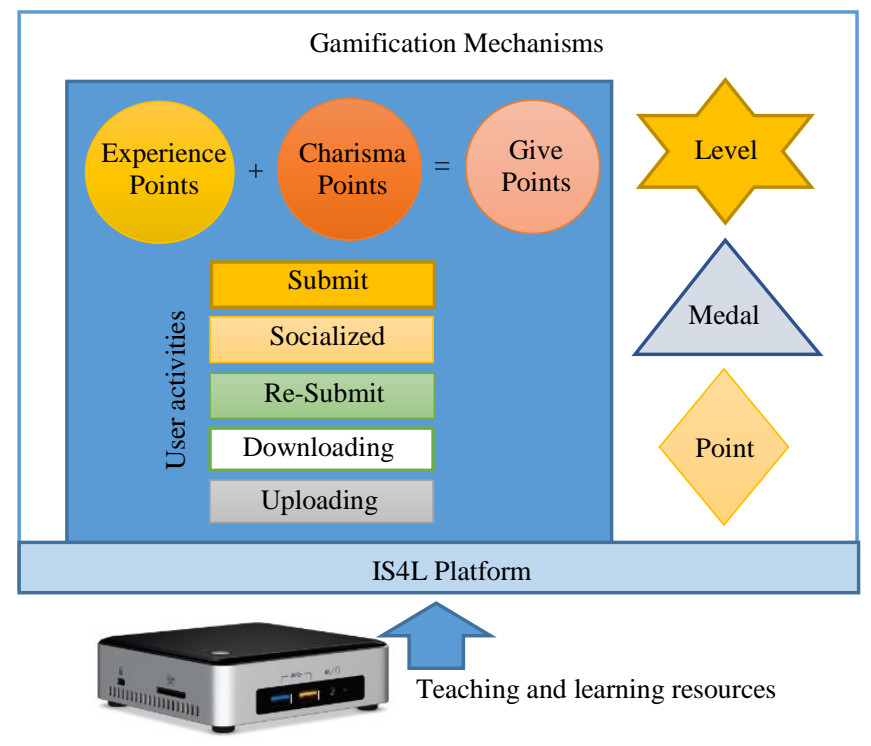

Fig. 2: The platform structure of IS4L

The platform structure in Figure 2 shows the activities that support IS4L as a gamification platform. The activities are provided to introduce and engage users in IPG with activities and educational content. Therefore the more user interacts with the application, and achieve each of the objectives, the higher is their ranking and 
status in the organization (IPG). This status is represented with badges, which describe the qualities and capabilities of this particular member to the organization, and the contribution to their information management process at the organizational level.

\section{Gamification model for resource sharing}

The main objective of IS4L is to increase the effectiveness, engagement, satisfaction and motivation of users. These objectives can be achieved through the use of game mechanics, dynamics and gamification. Management of IS4L will create the conditions under which users are motivated, satisfied, effective and efficient. Management of IS4L is an important part of the model. The architecture of model is presented in Fig. 3 which consists of seven elements. Model of IS4L, which includes elements of gamification must be based on appropriate management. The effectiveness of IS4L comes with the best practice of organizing, planning, staffing, leading and controlling activities. Here, the main important elements in IS4L are as follows:

- Technology - Technology is an infrastructure that enables the implementation of IS4L. The use of digital technologies and social networking has grown rapidly over the last decades, and these technologies are increasingly being incorporated into the teaching of higher education [8][9].

- Design - The lack of user profile analysis, appropriate design methods, and gamification schemas which are too simple, can lead to applications achieving results below than the expectations. While it is clear that gamification has produced some promising results, the design approach does come with a significant risk [10][11]. A good design must provide information which are: useful, usable, desirable, findable, accessible and credible [12].

- Administration - Administration of IS4L requires knowledge of the technology. Administration of technology and user is can be performed by using Learning Management Systems (LMS). Some LMS tools are used for instructional tasks that are performed to enable or prepare student's learning activities [13]. The most important is to enable lecturers to set up gamification and personalized learning activities using different learning contents, stored in the platform itself, in a LMS [14]. In addition to these systems, there are other requirements for the administration, which are an essential precondition for the reliable implementation of IS4L.

- People - The main objective of IS4L is to provide information through technology. IS4L must be organized in such a way that users are satisfied with. For good organization of IS4L it is necessary to know the users' characteristics, such as: level of education, area of expertise, age, occupation, gender, culture, skills, etc.

- Material - The design of the electronic version of materials does not differ significantly from traditional printed materials. Materials must be based on the same principles, which means that objectives must be clearly set. The material should be divided into separate sections or learning units and should be properly designed in terms of content and didactics.

\subsection{Game mechanics vs game dynamics}

In order to engage user's experiences through gamification context, it is necessary to consider the functioning of game mechanics and dynamics. Game mechanics and dynamics are two important tools related to gamification [15]. Game mechanics are related to rules and benefits that compose the game - features that make it challenging, fun, rewarding or any other emotion expected by game designers [16]. These emotions are the result of wishes and motivations, which are called game dynamics. Game mechanics are responsible for the functioning of the game components. It allows the user to have total control of the game levels and, with it, guides user's actions. On the other hand, dynamics can be defined as the interactions of users that apply the game mechanics [17]. It determines what every user is doing as a response to the system mechanics, individually and with other users. Game mechanics are built by tools, techniques and widgets used to gamify a website or application. By using them individually or collectively, it is possible to stimulate motivational aspects of users. Some of the most common game mechanics are:

- $\quad$ Points - Used to reward users through multiple dimensions and different categories. It can be used to manage different behaviors inside the same website or application. When points should stimulate a competition, it should be used as scores; on the opposite side, when the goal is to provide constant feedback to the user. For each individual progress should not be shown to other people [18]. Points can also be used to stimulate the participation of users.

- Levels - Indicate the users' accomplishment of a goal. The higher the level, the greater is the respect and status. Levels are usually defined as threshold points, in a way users can automatically level up based on their participation.

- Challenges, Trophies, Badges/Medals and Accomplishments - Challenges represent missions for user to accomplish and then give rewards for the execution. Trophies, badges or medals are the visible acknowledgment that indicate when the user has reached new levels and concluded challenges. The main mechanism to make efficient challenges and levels is to provide users with a place where they can show their accomplishments, such as a trophy shelf. Five psychological functions that medals can have in a context of social media [19]. The most important role of them is the goal-setting. Many times, the main rewards are fun and interesting while fulfilling goals. When the progress to reach a goal is presented to the user, the following badge will become more efficient.

- Virtual Goods - Non-physical and intangible objects that can be purchased using points collected by the users over time. Virtual goods is a good way to provide incentive to them to get more points and they also offer the possibility of personalizing something that will reflect their identity. Virtual goods can also be converted into points, badges/medals, discounts, credits and avatars. It is very common to use virtual coins in different situations including the trade mechanism to buy items and points to increase status and prestige [20].

- $\quad$ Classification Table, Ranking, Score Table - this mechanism shows the position of users compared to others. These tables are commonly used to manage and display the scores of users with the objective of using the competition as an incentive to the behaviour. The greatest benefit of implementing a classification table is the fact it provides contextual information on the progress of users that could have a motivating effect on the user.

People are motivated by the game mechanics due to its dynamics as people have fundamental needs and desires (reward, status, accomplishment, self-expression, and competition, among others). By selecting the proper set of game mechanics onto the platform, it is possible to create an experience that stimulates the behavior by satisfying one or more of those needs, such as:

- Reward - Tangible or intangible, the reward is presented after an action (that is, a behavior), with the intention of this behaviour to be repeated. In gamification, the main reward mechanism is the system of points or similar ideas.

- $\quad$ Status - Most people have the need to be recognized: fame, prestige, attention and, lastly, esteem and respect from others. In order to get it, the participants need to engage in some activities. Elements from game mechanics such as levelling up or obtaining items others still do not have work as a motivating feature.

- Accomplishments/ Fulfillment - Some people are driven by the need of accomplishing something difficult through pro- 
longed and repeated efforts, working towards the goals and to win. These good users tend to seek challenges and establish moderately difficult goals (but still achievable) and their greatest reward is the accomplishment of this completion.

- Self-Expression - Users need opportunities to express an autonomy and originality and, somehow, differentiate themselves from others. An example is the use of virtual products which could to create unique identity. Its can be obtained through rewards, presents or bought directly. The avatar of a person, for example, is one of the main ways of expression.

- Competition - It is possible to obtain the highest levels of performance when a competitor knows the winner will be rewarded. It happens because there is a kind of satisfaction by comparing individual performance with others.

Fig. 3 depicts the conceptual model of applying gamification elements in information sharing using resource as a service framework for Institut Pendidikan Guru Malaysia.

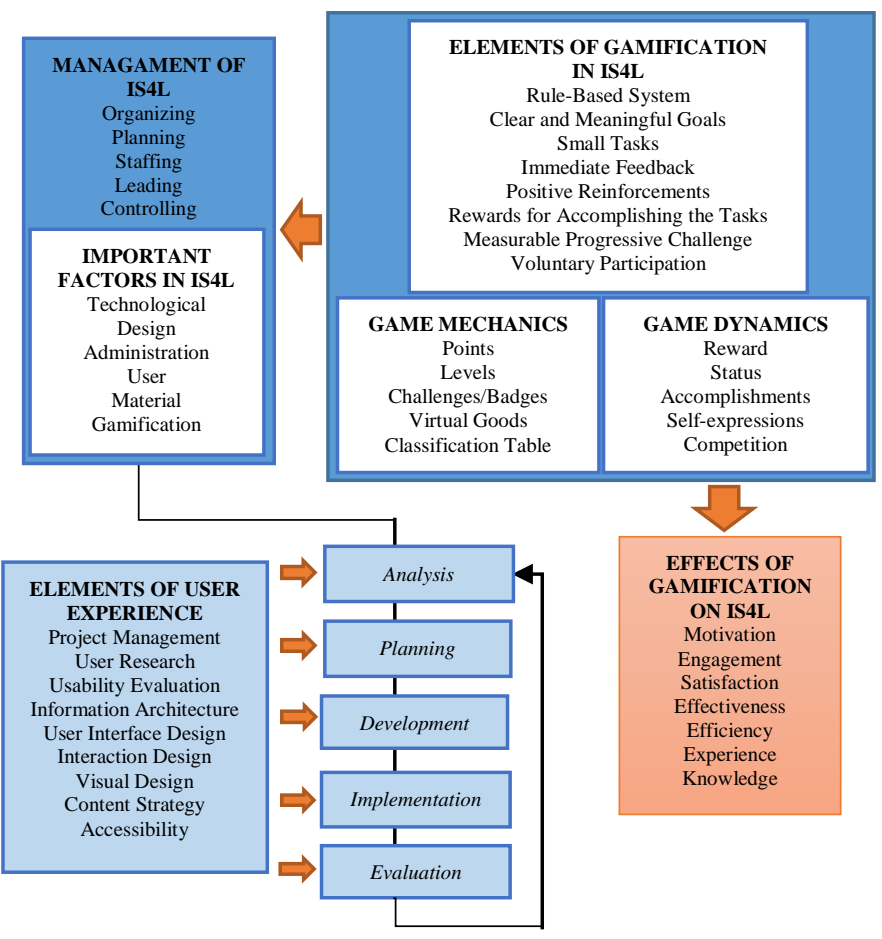

Fig. 3: Model of gamification in the field of IS4L in IPG

\section{Conclusion}

IPG faced problems to implement the concept of resource sharing among the lecturers and students. This article introduced the concept of gamification in resource sharing of teaching and learning materials. The framework is developed based on two elements of gamification which are game mechanics and game dynamics.

\section{Acknowledgement}

This study is partially funded by Ministry of Higher Education Malaysia (FGRS/1/2015 - Code: RR143). Special thanks to Universiti Sultan Zainal Abidin for providing facilities to develop and evaluate the proposed framework.

\section{References}

[1] Muhammad Al-Qurishi, Mabrook Al-Rakhami, Fattoh AlQershi, et al., "A Framework for Cloud-Based Healthcare Services to Monitor Noncommunicable Diseases Patient," Interna- tional Journal of Distributed Sensor Networks, vol. 2015, Article ID 985629, 11 pages, 2015. doi:10.1155/2015/985629

[2] Agmon Ben-Yehuda, O., Ben-Yehuda, M., Schuster, A., Tsafrir, D.: The resourceas-a-service (RaaS) cloud. In: USENIX Conference on Hot Topics in Cloud Computing (HotCloud) (2012) Game mechanics vs game dynamics

[3] Gutiérrez-Carreón, G., Daradoumis, T., \& Jorba, J. (2015). Integrating learning services in the cloud: An approach that benefits both systems and learning. Educational Technology and Society, 18(1), 145-157. Retrieved from www.scopus.com

[4] Washington Luna and José Luis Castillo Sequera (2015). Collaboration in the Cloud for Online Learning Environments: An Experience Applied to Laboratories. Retrieved Jun 21, 2017 from http://file.scirp.org/pdf/CE_2015080510312372.pdf

[5] Deterding, Sebastian \& Khaled, Rilla \& Nacke, Lennart \& Dixon, Dan. (2011). Gamification: Toward a definition. 12-15.

[6] Dergousoff, K., \& Mandryk, R. L. (2015). Mobile Gamification for Crowdsourcing Data Collection: Leveraging the Freemium Model, 1065-1074.

[7] David R Flatla, Carl Gutwin, Lennart E Nacke, Scott Bateman, and Regan L Mandryk. 2011. Calibration games: making calibration tasks enjoyable by adding motivating game elements. In Proc. of UIST'11. ACM, 403-412.

[8] Urh, M., Vukovic, G., Jereb, E., \& Pintar, R. (2015). The Model for Introduction of Gamification into E-learning in Higher Education. Procedia - Social and Behavioral Sciences, 197(February), 388-397. https://doi.org/10.1016/j.sbspro.2015.07.154

[9] Rahman, M. N. A., Saidu, A. N., \& Kadir, M. F. A. (2017). Dynamic Resource Sharing Model for Information Management in Malaysian Schools, 35, 89-95. https://doi.org/10.5829/idosi/wasj.2017.89.95

[10] Laurillard, D. (2006). E-learning in higher education. Changing higher education: The development of learning and teaching, 7184.

[11] Pedreira, O., García, F., Brisaboa, N., \& Piattini, M. (2015). Gamification in software engineering - A systematic mapping. Information and Software Technology, 57(1), 157-168. doi:10.1016/j.infsof.2014.08.007

[12] Browne, K., Anand, C., \& Gosse, E. (2014). Gamification and serious game approaches for adult

literacy tablet software. Entertainment Computing, 5(3), 135-146. doi:10.1016/j.entcom.2014.04.003

[13] Usability.gov. (2014). User Experience Basics. Retrieved July 24 2017 from http://www.usability.gov/what-and-why/userexperience.html

[14] Schoonenboom, J. (2014). Using an adapted, task-level technology acceptance model to explain why instructors in higher education intend to use some learning management system tools more than others. Computers and Education, 71, 247-256. doi:10.1016/j.compedu.2013.09.016

[15] Simões, J., Redondo, R. D., \& Vilas, A. F. (2013). A social gamification framework for a K-6 learning platform. Computers in Human Behavior, 29(2), 345-353. doi:10.1016/j.chb.2012.06.007

[16] Law, F. L., Kasirun, Z. M., \& Gan, C. K. (2011, December). Gamification towards sustainable mobile application. In Software Engineering (MySEC), $20115^{\text {th }}$ Malaysian Conference (pp. 349e353). IEEE.

[17] Bunchball, I. (2010). Gamification 101: An introduction to the use of game dynamics to influence behavior. White paper.

[18] Zichermann, G., \& Cunningham, C. (2011). Gamification by design: Implementing game mechanics in web and mobile apps. O'Reilly Media, Inc.

[19] Werbach, K., \& Hunter, D. (2012). For the win: How game thinking can revolutionize our business. Wharton Digital Press.

[20] Antin, J., \& Churchill, E. F. (2011). Badges in social media: A social psychologicaln perspective. In CHI 2011. Vancouver, BC: ACM. 